\title{
Evaluation of the Anxiety Level of Mothers of Children with Epilepsy during the COVID-19 Pandemic Period
}

\author{
Halil Celik $^{\mathrm{a}}$ Sadettin Burak Acikel ${ }^{\mathrm{b}}$ Fatih Mehmet Akif Ozdemir ${ }^{\mathrm{a}} \quad$ Erhan Aksoy $^{\mathrm{a}}$ \\ Ulkuhan Oztoprak $^{\mathrm{a}} \quad$ Ergin Cucu $^{\mathrm{a}} \quad$ Ozge Kucur $^{\mathrm{a}} \quad$ Nesrin Ceylan ${ }^{\mathrm{a}}$ Deniz Yuksel $^{\mathrm{a}}$ \\ aDepartment of Pediatric Neurology (DY) University of Health Sciences, Dr. Sami Ulus, Maternity and Children's \\ Health and Diseases Training and Research Hospital, Ankara, Turkey; ${ }^{b}$ Child and Adolescent Psychiatry Department, \\ University of Health Sciences, Dr. Sami Ulus, Maternity and Children's Health and Diseases Training and Research \\ Hospital, Ankara, Turkey
}

\section{Keywords}

Coronavirus disease 2019 · Pandemic · Childhood epilepsy · Maternal anxiety

\begin{abstract}
Background and Aim: Although anyone can be affected by the COVID-19 pandemic, it may cause additional concern for people with chronic conditions. Epilepsy is the most common neurological disease in childhood and adolescence. The aim of this study was to determine anxiety levels among the mothers of children under follow-up for epilepsy in our clinic during the COVID-19 pandemic. Methods: The study group consisted of the mothers of epilepsy patients who were under follow-up in the pediatric neurology outpatient clinic of the tertiary care center and were scheduled for a routine examination during the COVID-19 pandemic. The mothers' anxiety levels according to the Beck Anxiety Inventory and their opinions about COVID-19 in relation to their child were assessed and compared based on whether the mother/patient attended their appointments in person and whether the child had frequent or infrequent seizures. $\boldsymbol{R e}$ sults: There was no statistically significant difference in anxiety level between the mothers of 64 children with epilepsy who attended their appointment during the pandemic and
\end{abstract}

those of the mothers of 52 who did not attend their appointment. However, the mothers of children with frequent seizures had significantly higher anxiety levels. Conclusion: Anxiety level of mothers whose children have frequent seizures was significantly higher compared to mothers whose children have infrequent seizures. It is important to be aware about this point and using telemedicine approach in suitable population and postpone routine outpatient follow-up appointments as much as possible.

(c) 2021 S. Karger AG, Basel

\section{Introduction}

Epilepsy is the most common neurological disease of childhood and adolescence [1]. Although epilepsy can be successfully controlled with medication in $70-80 \%$ of patients, for the parents of children with epilepsy, their sense of losing control of their children combined with stigmatization by the society increases long-term family stress and impacts family dynamics. This usually gives rise to feelings of desperation and fear in parents, which may lead to overprotection and coddling of their children $[2,3]$. Families must confront many problems when their child is diagnosed with epilepsy $[1,4-7]$. The families of 
children with epilepsy encounter issues such as psychosocial and economic problems, anxiety, depression, sleep problems, family problems, and reduced quality of life [5-13].

The WHO declared novel coronavirus disease 2019 (COVID-19) a pandemic on March 11, 2020. At present, COVID-19 is still spreading rapidly worldwide. COVID-19 has various manifestations ranging from asymptomatic to mild to severe clinical presentations with or without pneumonia $[14,15]$. The pandemic not only affects people as an infectious disease but also the resulting state of panic and the precautionary measures implemented have an adverse effect on people's mental health [16-17]. The COVID-19 pandemic has also affected the medical follow-up of epilepsy patients, as all routine follow-up was halted (affected). Moreover, since COVID-19 follows a more severe course in patients with chronic disease [18], it is believed that epilepsy patients and their families might have increased anxiety during the pandemic and that this may affect their daily functioning. The aim of this study was to determine the anxiety levels of the mothers of patients who were under follow-up for epilepsy in our clinic and had an appointment scheduled during the COVID-19 pandemic (both those who were and were not able to attend their appointments) and to evaluate the secondary effects caused by COVID-19. Since the primary caregiver of children admitted to our pediatric neurology unit is usually mothers, we conducted our study with mothers. In addition, we aimed to compare the anxiety of mothers of children with more frequent seizures with the anxiety of mothers of children with less frequent seizures because COVID-19 affects more seriously individuals with chronic conditions.

\section{Materials and Methods}

During the COVID-19 pandemic, our center was designated a COVID-free hospital by the Turkish Ministry of Health. In addition to continuing routine in-person patient examinations, a telephone line was established to provide information via the telemedicine approach for patients who were unable to come to the hospital. Since the beginning of the pandemic, the contact information for this special phone line created for the pediatric neurology outpatient clinic was displayed on the hospital's website, and the line was answered by pediatric neurologists.

Our study group consisted of the mothers of patients who were being followed up for epilepsy in the pediatric neurology outpatient clinic and were scheduled for follow-up during the COVID-19 pandemic. Both those who were and were not able to attend their appointments in person were included. The study was first approved by the Ministry of Health and the Ethics Review Committee of Ankara City Hospital (EC No. 2020-751). Written

Maternal Anxiety Level in COVID-19

Pandemic and verbal informed consent forms were signed by all participants before the study. The mothers of patients who could not attend their routine follow-up appointments were contacted by phone, and those who agreed to participate in the survey were included in the study group. Because there is no official telemedicine platform in our country when this study was conducted, we have used phone call. Their child's age, duration of epilepsy, and seizure frequency were recorded for all participants. Patients with a history of at least 2 afebrile seizures and no seizures since starting antiepileptic therapy were classified as having infrequent seizures; patients who had $>1$ seizure per month despite the use of 2 or more major antiepileptic drugs at the appropriate dose and duration were classified as having frequent seizures. Information such as age, education level, method of transport to the hospital, employment status, number of children, and family type was recorded for all mothers participating in the study.

The patients' mothers answered a questionnaire about their thoughts on COVID-19 and completed the Beck Anxiety Inventory. The COVID-19 questionnaire was administered to the mothers face-to-face or by telephone interview (Table 1).

The Beck Anxiety Inventory is a self-report tool developed by Beck et al. [19] to assess the frequency of anxiety symptoms in adolescents and adults. The scale consists of 21 items rated on a 4-point Likert-type scale ranging from 0 (not at all) to 3 (severely). Higher total score indicates higher level of anxiety, and there is no cutoff score for this inventory [19]. The Turkish validity and reliability study was conducted by Ulusoy et al. [20]

Inclusion criteria for the study were that the children had been followed at least 6 months for epilepsy and had no additional disease other than epilepsy, and the mother was between 20 and 60 years of age, had no psychiatric disorder (e.g., anxiety disorder, depression, and personality disorders) and was taking no psychiatric medication, had no cognitive impairment based on clinical interview, and consented to participating in the study. Exclusion criteria were the mothers having a diagnosed psychiatric disorder or any other diagnosed neurological disorder that may affect anxiety at the time of the study and refusing to participate in the study.

\section{Statistical Analyses}

Statistical analyses were performed using IBM SPSS Statistics Version 22.0 for Windows statistical software package (IBM Corp., Armonk, NY, USA). Numbers and percentages were reported for discrete variables; continuous variables were expressed as mean and standard deviation for data with normal distribution and as median and interquartile range for nonnormally distributed data. $\chi^{2}$ test was used to compare nonparametric data; the Mann-Whitney $U$ test was used in comparisons of nonnormally distributed continuous data and independent-samples $t$ test for normally distributed continuous data. $p$ value $<0.05$ was considered statistically significant.

\section{Results}

The study sample consisted of 116 mothers of patients who were followed for epilepsy in our department. Sixty four of them were evaluated by face-to-face interview, and 52 of them were evaluated by telephone interview. Of 
Table 1. Questions which were asked to mothers

\begin{tabular}{|c|c|}
\hline $\begin{array}{l}\text { Q1. Age } \\
20-39 \text { years } \\
40-60 \text { years }\end{array}$ & $\begin{array}{l}\text { Q11. Do you comply with social distancing in the community and use } \\
\text { a mask? } \\
\text { Yes } \\
\text { No }\end{array}$ \\
\hline $\begin{array}{l}\text { Q2. Level of education } \\
\text { Primary school } \\
\text { High school } \\
\text { University graduated }\end{array}$ & $\begin{array}{l}\text { Q12. Do you follow the COVID-19-related disease table announced } \\
\text { by the Ministry of Health daily? } \\
\text { Yes } \\
\text { No }\end{array}$ \\
\hline $\begin{array}{l}\text { Q3. Where do you live? } \\
\text { Ankara } \\
\text { Other }\end{array}$ & $\begin{array}{l}\text { Q13. How likely do you think your child diagnosed with epilepsy } \\
\text { would get a corona virus infection? } \\
\text { 0\% } \\
25 \% \\
50 \% \\
75 \% \\
100 \%\end{array}$ \\
\hline $\begin{array}{l}\text { Q5. Age of the patient? } \\
6 \text { months-2 years } \\
2-10 \text { years } \\
>11 \text { years }\end{array}$ & $\begin{array}{l}\text { Q15. How much does your travel to the hospital increase your child's } \\
\text { risk of coronavirus infection? } \\
\text { 0\% } \\
25 \% \\
50 \% \\
75 \% \\
100 \%\end{array}$ \\
\hline $\begin{array}{l}\text { Q7. Epilepsy follow-up time? } \\
6 \text { months-1 year } \\
>1 \text { year }\end{array}$ & $\begin{array}{l}\text { Q17. How much does your waiting time in the hospital increase your } \\
\text { child's risk of coronavirus infection? } \\
\text { 0\% } \\
25 \% \\
50 \% \\
75 \% \\
100 \%\end{array}$ \\
\hline $\begin{array}{l}\text { Q8. Your child's seizure frequency? } \\
\text { Frequent daily seizure } \\
\text { Several seizures a month } \\
>1 \text { year seizure-free }\end{array}$ & $\begin{array}{l}\text { Q18. Have you ever performed hand washing or disinfection while } \\
\text { waiting in the hospital? } \\
\text { Yes } \\
\text { No }\end{array}$ \\
\hline $\begin{array}{l}\text { Q9. Do you have any chronic diseases? } \\
\text { Yes } \\
\text { No } \\
\text { Explain if your answer is yes }\end{array}$ & $\begin{array}{l}\text { Q19. Have you ever heard of the concept of telemedicine? } \\
\text { Yes } \\
\text { No }\end{array}$ \\
\hline
\end{tabular}


Table 1 (continued)

Q10. Is there another individual with a chronic illness in the home?

Yes

No

Explain if your answer is yes
If your answer is yes, is it appropriate to be used in your future follow-ups?

Do not agree

Undecided

Agree mothers, $77.6 \%(n=90)$ were $20-39$ years old and $22.4 \%$ $(n=26)$ were $40-60$ years old. In terms of the patients' ages, $8.6 \%(n=10)$ were younger than 2 years of age, $70.7 \%(n=$ $82)$ were $2-10$ years old, and $20.7 \%(n=24)$ were older than 10 years. Maternal educational level was primary school for 42.2\% ( $n=49)$, high school for $54.3 \%(n=63)$, and university for $3.4 \%(n=4)$. In terms of residence, $60.3 \%(n=70)$ of the mothers/patients lived in the same city as the hospital, while $39.7 \%(n=46)$ did not live in the same city and traveled to our department for treatment. When seizure frequency was evaluated, $62.1 \%$ of patients $(n=72)$ had no seizures for over 1 year (infrequent seizures), while $37.9 \%$ $(n=44)$ had $>1$ seizure per month (defined as frequent seizures). Epilepsy duration was over 1 year in $43.1 \%$ of patients $(n=50)$ and $<1$ year in $56.9 \%(n=66)$. The demographics of the sample are presented in Table 2.

In the COVID-19 opinion questionnaire, all participants answered yes when asked if they followed the chart of COVID-19 infection rates published by the Ministry of Health on a daily basis and whether they practiced social distancing and wore a mask when in public. During the COVID-19 pandemic, some of the mothers chose to present to the outpatient clinic for follow-up, while others chose to call their child's neurologist. Comparison of Beck Anxiety Inventory scores between these groups showed no significant difference $(t=0.803, p=0.423)$. We also compared Beck Anxiety Inventory scores between mothers according to their children's seizure frequency and observed that the mothers of children with frequent seizures had significantly higher scores compared to the mothers of children with infrequent seizures $(t=3.969, p<0.001$, Cohen's $d=0.759)$. When anxiety scores were compared according to education level, mothers who were high school graduates were more anxious than primary school-educated mothers, with the difference nearly reaching statistical significance $(t=$ $-1.925, p=0.057)$. The results of analysis are presented in Table 3.

During data collection, the mothers were asked to rate how much their visit to the hospital increased their risk of coronavirus infection as $0,25,50,75$, or $100 \%$ according to their own perceptions. In $\chi^{2}$ analysis, mothers

Maternal Anxiety Level in COVID-19

Pandemic
Table 2. Demographics of the sample

\begin{tabular}{|c|c|c|c|c|}
\hline & \multicolumn{2}{|c|}{ Physically admitting } & \multicolumn{2}{|c|}{ Telephone interview } \\
\hline & $N$ & $\%$ & $N$ & $\%$ \\
\hline Participants, $n$ & 64 & 55.2 & 52 & 44.8 \\
\hline \multicolumn{5}{|l|}{ Age of parents } \\
\hline 20-39 years & 41 & 45.5 & 49 & 54.5 \\
\hline $40-60$ years & 23 & 88.4 & 3 & 11.6 \\
\hline \multicolumn{5}{|l|}{ Age of patients } \\
\hline$<2$ years & 2 & 20 & 8 & 80 \\
\hline $2-10$ years & 46 & 56.1 & 36 & 43.9 \\
\hline$>10$ years & 16 & 66.6 & 8 & 33.4 \\
\hline \multicolumn{5}{|c|}{ Maternal educational level } \\
\hline Primary school & 36 & 73.4 & 13 & 26.6 \\
\hline High school & 24 & 38.1 & 39 & 61.9 \\
\hline University & 4 & 100 & 0 & 0 \\
\hline \multicolumn{5}{|l|}{ Seizure frequency } \\
\hline Frequent seizures & 26 & 59.1 & 18 & 40.9 \\
\hline Infrequent seizures & 38 & 52.8 & 34 & 47.2 \\
\hline
\end{tabular}

whose children had frequent seizures rated the risk as significantly higher than those whose children had infrequent seizures $\left(\chi^{2}=8.087, p=0.044\right)$. The mothers of children with frequent seizures also expressed significantly higher risk when asked how much their travel to the hospital and how much the waiting time in the hospital increased their children's risk of coronavirus infection. The detailed results are shown in Table 4.

In the COVID-19 opinion survey, all of the mothers of patients who came to their hospital appointments answered yes when asked if they had performed hand washing or disinfection while waiting at the hospital. The detailed results are shown in Table 4.

When asked what the likelihood was of their epileptic child contracting coronavirus infection, there was no statistically significant difference in the answers given by the mothers of the children who did and did not come to the outpatient clinic and those who had infrequent and frequent seizures $(p=0.470)$. The detailed results are shown in Table 4. 
Table 3. Comparison of BAI scores between groups

\begin{tabular}{|c|c|c|c|c|c|c|c|}
\hline & \multicolumn{2}{|c|}{ Physically admitting } & \multicolumn{2}{|c|}{ Telephone interview } & \multicolumn{3}{|c|}{ Statistics } \\
\hline & mean & $\mathrm{SD}$ & mean & $\mathrm{SD}$ & $t$ & $p$ value & Cohen's $d$ \\
\hline & 4.85 & 4.41 & 4.25 & 3.58 & 0.803 & 0.423 & \\
\hline \multirow[t]{2}{*}{ BAI total score } & \multicolumn{2}{|c|}{ Frequent seizures } & \multicolumn{5}{|c|}{ Infrequent seizures } \\
\hline & 6.38 & 4.18 & 3.48 & 3.57 & 3.969 & $<0.001$ & 0.759 \\
\hline \multirow[t]{2}{*}{ BAI total score } & \multicolumn{2}{|c|}{ High school graduated } & \multicolumn{5}{|c|}{ Primary school graduated } \\
\hline & 3.79 & 4.19 & 5.26 & 3.88 & -1.925 & 0.057 & \\
\hline
\end{tabular}

BAI, Beck Anxiety Inventory; SD, standard deviation.

Table 4. Comparison of COVID-19 perceptions of mothers of patients with low and high seizure frequency

\begin{tabular}{|c|c|c|c|c|c|c|c|c|c|}
\hline \multicolumn{2}{|c|}{$0 \%$} & \multicolumn{2}{|c|}{$25 \%$} & \multicolumn{2}{|c|}{$50 \%$} & \multicolumn{2}{|c|}{$75 \%$} & \multirow[b]{2}{*}{$\chi^{2}$} & \multirow[b]{2}{*}{$p$ value } \\
\hline$N$ & $\%$ & $N$ & $\%$ & $N$ & $\%$ & $N$ & $\%$ & & \\
\hline
\end{tabular}

"How much does your visit to the hospital increase your risk of coronavirus infection?"

$\begin{array}{llllllllll}\text { More frequent seizure } & 10 & 22.7 & 28 & 63.6 & 6 & 13.6 & 0 & 0 & 8.087 \\ \text { Less frequent seizure } & 29 & 40.3 & 40 & 55.6 & 2 & 2.8 & 1 & 1.4 & \end{array}$

"How much does your travel to the hospital increase your child's risk of coronavirus infection?"

$\begin{array}{lllllllllll}\text { More frequent seizure } & 15 & 34.1 & 28 & 63.6 & 1 & 2.3 & 0 & 0 & 6.758 & 0.034 \\ \text { Less frequent seizure } & 42 & 58.3 & 28 & 38.9 & 2 & 2.8 & 0 & 0 & & \end{array}$

"How much does your waiting time in the hospital increase your child's risk of coronavirus infection?"

\begin{tabular}{lrlllllllll} 
More frequent seizure & 9 & 20.5 & 31 & 70.5 & 4 & 9.1 & 0 & 0 & 6.184 & 0.045 \\
Less frequent seizure & 29 & 40.3 & 41 & 56.9 & 2 & 2.8 & 0 & 0 & & \\
\hline
\end{tabular}

"How likely do you think you would get a coronavirus infection?"

\begin{tabular}{llllllllll} 
More frequent seizure & 0 & 0 & 7 & 25.9 & 18 & 66.7 & 2 & 7.4 & 2.412 \\
Less frequent seizure & 0 & 0 & 8 & 25.8 & 23 & 74.2 & 0 & 0 & \\
\hline
\end{tabular}

"How likely do you think one of your family members would get a coronavirus infection?"

$\begin{array}{lllllllllll}\text { More frequent seizure } & 24 & 54.5 & 18 & 40.9 & 2 & 4.5 & 0 & 0 & 1.508 & 0.470 \\ \text { Less frequent seizure } & 45 & 62.5 & 26 & 36.1 & 1 & 1.4 & 0 & 0 & & \end{array}$

"How likely do you think your child diagnosed with epilepsy would get a coronavirus infection?"

$\begin{array}{llllllllllll}\text { More frequent seizure } & 16 & 36.4 & 26 & 59.1 & 2 & 4.5 & 0 & 0 & 4.758 & 0.093 \\ \text { Less frequent seizure } & 41 & 56.9 & 28 & 38.9 & 3 & 4.2 & 0 & 0 & & \end{array}$

"How likely do you think your child would get a coronavirus infection from the doctor who followed your child?"

$\begin{array}{llllllllll}\text { More frequent seizure } & 24 & 54.5 & 20 & 45.5 & 0 & 0 & 0 & 0\end{array}$

$\begin{array}{lllllllll}\text { Less frequent seizure } & 47 & 65.3 & 25 & 34.7 & 0 & 0 & 0 & 0\end{array}$

$1.325 \quad 0.250$

More frequent seizure: $>1$ seizure in 1 month. Less frequent seizure: no seizure for $>1$ year.

When asked to what extent they believed their child would contract coronavirus infection from the doctor examining him/her during the routine epilepsy follow-up appointment, 24 (54.5\%) of the mothers of children with frequent seizures said there was no risk of transmission and $20(45.5 \%)$ said there was a $25 \%$ chance of transmission, while among the mothers of children with infrequent seizures, $47(65.3 \%)$ said there was no risk and 25 $(34.7 \%)$ said there was a $25 \%$ chance $(p=0.25)$. The detailed results are shown in Table 4. 
When asked if they had ever heard of the concept of telemedicine, $8(6.9 \%)$ of the mothers in our study said they had and 108 (93.1\%) said they had not. All of those who knew about telemedicine expressed positive opinions regarding its use.

\section{Discussion}

Epilepsy is a chronic disease that affects children's cognitive and behavioral functioning. Children are important to their parents, and when a child develops a disability or health problem, their parents often experience various emotional phases. While COVID-19 can affect everyone worldwide, it may cause an additional anxiety in people with chronic health problems [21]. Based on the evaluation by the WHO, it might threaten the mental health of affected populations. According to the observations and studies performed to date, no correlation has been reported between epilepsy and COVID-19. In our study, there was no statistically significant difference in anxiety level between the mothers of 64 epilepsy patients who attended their follow-up appointment during the pandemic and the mothers of 54 epilepsy patients who did not attend their appointment. The admission of our patients to the hospital was not affected by the anxiety level of their mothers.

In a study of 50 children with epilepsy and their mothers, Pekcanlar et al. [22] investigated the mothers' anxiety and depression levels, parents' attitudes, and family functioning. Refractory epilepsy was associated with higher anxiety levels. Williams et al. [13] evaluated the anxiety levels of 200 parents (179 mothers and 21 fathers) of children with epilepsy and reported that mean anxiety values were within the normal range and were not associated with seizure type or frequency. In our study, higher anxiety levels were observed in the mothers of children with frequent seizures. Since anxiety level of the mothers of children who had frequent seizures before pandemic was not known in our study, the association between the increased anxiety level in this group and the pandemic could not be evaluated.

Chapieski et al. [3] showed that mothers with higher anxiety levels were less educated. However, when the mothers in our study were compared based on educational level, it was found that mothers with at least a high school degree had higher anxiety scores than others. This finding suggests that more educated mothers may be paying more attention to scientific information and media reports.

In our study, mothers were asked to what extent they thought coming to the hospital increased their risk of coronavirus infection and how much their traveling to the hos-

Maternal Anxiety Level in COVID-19 Pandemic pital and waiting in the hospital before their appointment increased their child's chance of coronavirus infection. When their responses were compared, no significant difference was detected between those who came to the hospital and those who did not, whereas the mothers of children with frequent seizures believed the risk of infection was significantly higher for all 3 questions compared to mothers whose children had infrequent seizures. It was thought that the perceptions of the possibility of coronavirus transmission were affected more negatively because the anxiety level of the mothers of children with frequent seizures was high. When evaluated in terms of maternal age, we found that while the rates of choosing telephone interview and physically admitting were equal in mothers between the ages of 20 and 39, the rate of choosing telephone interview was lower in mothers between the ages of 40 and 60 . We think that these data may be related to the fact that younger mothers are more prone to using telemedicine and telephone calls, a new concept, and older mothers prefer more traditional methods of patient examination. Also, the mothers of children under 2 years old prefer telephone interview more while the mothers over 10 years old prefer physically admitting. We think that these results are consistent with each other in terms of mother age and preferred method.

In our study, when mothers were asked for their opinion on the likelihood their child would be infected with coronavirus by the doctor that examined him/her during the routine epilepsy follow-up, $61 \%$ responded that there was no chance of transmission, while $39 \%$ of the participants replied that there may be a low rate of transmission. This finding is important in terms of how safe clinicians are perceived to be in terms of transmission and protection.

Children with well-controlled epilepsy and no other health problems who contract COVID-19 are usually asymptomatic or experience mild symptoms [23]. In our study, there was no other chronic disease other than epilepsy, and none of our patients were infected with coronavirus during the study period. Therefore, we could not evaluate the severity of our patients' coronavirus infection.

As in all fields, social isolation due to the COVID-19 pandemic is being implemented in the field of healthcare and requires minimization of physical contact between patients and doctors. This started to negatively affect not only patients with chronic diseases, but also the doctors who want to monitor their patients at specific intervals. Neurology patients are the group that has felt the greatest impact of this situation. One of the methods that ensure the continuity of healthcare in such extraordinary situations is telemedicine. Telemedicine is the use of information and communication systems for the provision of 
healthcare services in clinical practice, treatment, and patient follow-up. The objectives of the telemedicine approach include enabling everyone to receive quality healthcare services under more equal conditions and at lower cost and facilitating healthcare in situations that limit access to health workers, such as epidemics and earthquakes [24]. In our study, we observed that a very low proportion of the participants, only $6.9 \%$, reported having heard of telemedicine before, while all those who knew about telemedicine expressed positive opinions about using it. This shows that a significant portion of our patients still do not know the concept of telemedicine.

\section{Conclusion}

We have found that mothers of children with frequent seizures had significantly higher anxiety scores compared to the mothers of children with infrequent seizures. Also, we have provided descriptive data about hospital admission and telemedicine during the COVID-19 period among mothers whose children have epilepsy. Our study has certain limitations. First, our sample is relatively small. Second, there were no healthy control groups in order to compare anxiety levels. We could not include healthy control groups because of reduced admission to our hospital due to pandemic. We did not ask an openended question about the reason for mothers to choose whether to come in person or have their appointment by telephone. This would be useful for determining the possible reasons of mother's anxiety. In addition, we did not conduct a diagnostic interview, and we have measured anxiety levels with a self-reported scale.

We think that to reduce anxiety during this period, it should be ensured that epilepsy patients and their families continue their routine lives and do not disrupt their med- ication/sleep patterns. Providing information and fostering confidence that they can contact their doctor via phone or e-mail when necessary can help alleviate the concerns of patients and their relatives. Although the sample size is small, we think that the results of our study are important because there are few studies on this issue in children.

\section{Statement of Ethics}

The study was first approved by the Ministry of Health and the Ethics Review Committee of Ankara City Hospital (EC No. 2020751). Written and verbal informed consent forms were signed by all participants before the study. The mothers of patients who could not attend their routine follow-up appointments were contacted by phone, and those who agreed to participate in the survey were included in the study group.

\section{Conflict of Interest Statement}

The authors declare that they have no conflicts of interest.

\section{Funding Sources}

The authors received no financial support for the research, authorship, and/or publication of this article.

\section{Author Contributions}

H.C., D.Y., and S.B.A. contributed to the conception and design of the study and analysis and interpretation of data. F.A.M.Ö. participated in the design and conceptualization of the study, including the selection and development of the clinical rating scales. E.A., U.O., N.C., E.C., O.K., and D.Y. contributed to the conduct of the study and data collection. H.C. wrote the manuscript. All the authors have agreed to be accountable for all aspects of the study and have approved the final version of the manuscript.

\section{References}

1 Shinnar S, Pellock JM. Update on the epidemiology and prognosis of pediatric epilepsy. J Child Neurol. 2002;17(Suppl 1):S4-17.

2 Rodenburg R, Stams GJ, Meijer AM, Aldenkamp AP, Dekovic M. Psychopathology in children with epilepsy: a meta-analysis. J Pediatr Psychol 2005;30:453-68.

3 Chapieski L, Brewer V, Evankovich K, Culhane-Shelburne K, Zelman K, Alexander A. Adaptive functioning in children with seizures: impact of maternal anxiety about epilepsy. Epilepsy Behav. 2005;7:246-52.

4 Baykan Z, Baykan A, Naçar M. Satisfaction with life and cope of mothers with epileptic. Child New Med J. 2010;27:174-7.
5 Jensen MP, Liljenquist KS, Bocell F, Gammaitoni AR, Aron CR, Galer BS, et al. Life impact of caregiving for severe childhood epilepsy: results of expert panels and caregiver focus groups. Epilepsy Behav. 2017;74:13543.

6 Fazlıŏlu K, Hocaoğlu Ç, Sönmez FM. Impact of Childhood Epilepsy on the Family. Curr Approaches Psychiatry. 2010;2:190-205.

7 Harden J, Black R, Chin RFM. Families' experiences of living with pediatric epilepsy: a qualitative systematic review. Epilepsy Behav. 2016;60:225-37.

8 Lv R, Wu L, Jin L, Lu Q, Wang M, Qu Y, et al. Depression, anxiety and quality of life in par- ents of children with epilepsy. Acta Neurol Scand. 2009;120(5):335-41.

9 Taylor J, Jacoby A, Baker GA, Marson AG. Self-reported and parent-reported quality of life of children and adolescents with new-onset epilepsy. Epilepsia. 2011;52(8):1489-98.

10 Ferro MA, Speechley KN. Stability of latent classes in group-based trajectory modeling of depressive symptoms in mothers of children with epilepsy: an internal validation study using a boot strapping procedure. Soc Psychiatry Psychiatr Epidemiol. 2013;48:1077-86.

11 Shaki D, Goldbart A, Daniel S, Fraser D, Shorer Z. Pediatric epilepsy and parental sleep quality. J Clin Sleep Med. 2011;7(5):502-6. 
12 Akay AP, Kurul SH, Ozek H, Cengizhan S, Emiroğlu N, Ellidokuz H. Maternal reactions to a child with epilepsy: depression, anxiety, parental attitudes and family functions. Epilepsy Res. 2011;95:213-20.

13 Williams J, Steel C, Sharp GB, DelosReyes E, Phillips T, Bates S, et al. Parental anxiety and quality of life in children with epilepsy. Epilepsy Behav. 2003;4(5):483-6.

14 Modi AC. The impact of a new pediatrice pile psy diagnosis on parents: parenting stress and activity patterns. Epilepsy Behav. 2009;14: 237-42.

15 Duffy VL, Vessey JA. A randomized controlled trial testing the efficacy of the creating opportunities for parent empowerment (COPE) program for parents of children with epilepsy and other chronic neurological conditions. J Neurosci Nurs. 2016;48:166-74.
16 Li Q, Guan X, Wu P, Wang X, Zhou L, Tong $\mathrm{Y}$, et al. Early transmission dynamics in $\mathrm{Wu}-$ han, China, of novel coronavirus-infected pneumonia. N Engl J Med. 2020;382(13): 1199-207.

17 Zhu N, Zhang D, Wang W, Li X, Yang B, Song $\mathrm{J}$, et al. A novel coronavirus from patients with pneumonia in China, 2019. N Engl J Med. 2020;382(8):727-33.

18 Cao W, Fang Z, Hou G, Han M, Xu X, Dong $\mathrm{J}$, et al. The psychological impact of the COVID-19 epidemic on college students in China. Psychiatry Res. 2020;287:112934.

19 Beck AT, Epstein N, Brown G, Steer RA. An inventory for measuring clinical anxiety: psychometric properties. J Consult Clin Psychol. 1988;56:893-7.
20 Ulusoy M, Şahin N, Erkman H. Turkish version of the Beck anxiety inventory: psychometric properties. J Cogn Psychother. 1998; $12: 28-35$

21 CDC COVID-19 Response Team. Preliminary estimates of the prevalence of selected underlying health conditions among patients with coronavirus disease 2019: United States, February 12-march 28, 2020. MMWR Morb Mortal Wkly Rep 2020;69:382-6.

22 Pekcanlar AA, Hiz Kurul S, Ozek H, Cengizhan S, Emiroglu N, Ellidokuz H. Maternal reactions to a child with epilepsy: depression, anxiety, parental attitudes and family functions. Epilepsy Res. 2011;3:213-20.

23 Ekeland AG, Bowes A, Flottorp S. Effectiveness of telemedicine: A systematic review of reviews. Int J Med Inform. 2010;79:736-71.

$24 \mathrm{Lu} \mathrm{Q}$, Shi Y. Coronavirus disease (COVID-19) and neonate: what neonatologist need to know. J MedVirol. 2020 Jun;92(6): 564-7. 